\title{
Harmonized Standards for Development and Implementation of Information System in the Insurance Industry of Kosovo
}

\author{
Edmond Beqiri \\ University of Peja, "Haxhi Zeka" Kosovo \\ Besnik Zekaj \\ PhD Candidate UET, Tirana \\ Violeta Beqiri
}

European Vision University

Doi:10.5901/ajis.2015.v4n2s1p48

\begin{abstract}
Rapid innovations in information technology have made big impact in the insurance industry. The use of information technology for the insurance operations is strategic, in the sense that there is a direct impact on the productivity of resources, and a major impact on reducing the company's costs for its activities. Almost all modern business organizations are using and are becoming increasingly dependent on the application of information technologies. The information with complete and reliable data is necessary to participate in the tough competition that exist worldwide. As a result of this, competition is day by day increasing the demand for the Business Information Systems. To have a complete overview on the role and application of information technology in the insurance industry, in the paper we intend to present the importance of facilitating the IT application, of different operators and insurance companies. The paper provides a brief overview of the present situation of insurance branch in Kosovo, which is mostly depended by the Information Systems, at all kind of insurance activities. Information Technology, not only helps in the daily business of insurance companies but it has become an imperative to it. Authors made the research in various insurance companies and have analyzed accurate information on work done by operators in the field. The use of the online insurance system or of e-insurance, represents the fact that the IT revolution creates unprecedented basis for activities in financial growth all over the globe.
\end{abstract}

Keywords: Information, Technology, Insurance,Kosovo, Networks, IS, Business, MIS.

\section{Indroduction}

Use of the information technology in insurance industries is a necessity of today and has the strategic importance in the sense that it has a direct impact on labor productivity and it reduces costs for companies and their activities. By utilizing Information Technology, the insurance companies will be informed on market needs and this improves sales, reduces cost, reduces risk and makes possible to become even more competitive in the market. Also, the paper discusses further fact that the modern information technology increases the ability of people to access and analyze data much more effectively than previous technologies, by trained individuals or by groups that use this technology to insurance companies where they operate.

The Information in the insurance industry relies on computer technology and communication and enables a new approach of working in the course of its development in general. Like no other field in the insurance business sector, information technology has changed the mode of operation, during which the cult of physical labor was replaced with knowledge and with automation. Application of information technology in the insurance sector is particularly important to systems of management and to automation of this field.

With the unique design of the TPL policy which includes: preparation, installation and the use of the computer system for online filling and administration of the TPL policy, we can say freely that the insurance market in Kosovo has entered in a new development phase, with adapting of modern rules and technics applicable in the countries of developed world (TPL = third party liability. Useful if you got into an accident where you hit a person), .

The main goal of treatment of this research paper, in the first place is to have more complete overview of the role 
and application of information technology in the insurance industry. The paper presents a detailed overview on the importance of facilitating during its application at work of the various operators and insurance companies, consequently resulting with better services to customers.

We have also noted that with the advent of private insurance companies in the insurance market, competition became stronger and more intense, as well as they have invested on information technology, which has played its role in the insurance sector.

Although information technology is not new in this sector, we can still notice that it can be improved every day, in all of the important departments, such as: accounting issues and policies, services, processing of claims, risk management, etc.

The paper refers to general practice research, that has been made in various insurance companies, and as such provides the accurate figures that are done by operators in the field of insurance.

\section{Insurance Company as a New Financial Instrument in Kosovo}

Insurance Industry, in the phase of rapid developments that has experienced Kosovo after the war, especially with the privatization of state companies and with the establishment of private companies, resulted with the creating of a general competitive insurance and financial market in Kosovo. The Establishment of a legal infrastructure, has been institutional base for the functioning of financial institutions, and among them the insurance companies. The term "insurance", unless the economic importance, has other general legal and technical importance, according to its etymological meaning of the concept of faith in something protective, safety, warranty, trust etc. But what else guarantee in words, who should do what, to whom is needed, in what manner is insured, from what is the client protected?

The principle of working in insurance, represents a chain of values in a social reproduction, while the success is supported with the development of the principles of economics and business. The whole essence of insurance, is based on providing clients conditions and guarantees (insurance part) by creating a partnership and a sincere trust, from the moment of conclusion of the contract (cutting of the policy), with taking responsibility within the time limit (specified by the start and expiry date). The contract with the insurance company bought by client risk, takes responsibility to a third party (the shuttle damaged party).

\section{Insurance Companies that are Operating in Kosovo}

The Central Bank of Kosovo (CBK) is an institution that has authority for licensing, as well control of issuers in the banking system .

In the Kosovar market today operate a large number of insurance houses. When we say large number, we consider small population and number of vehicles in relation to insurance companies.

Insurance companies that are licensed to operate in Kosovo environment are:
I.C. Croatia Osiguranje;
I.C. Dardania;
I.C. Elsig;
I.C. Ilyria;
I.C. Insig-Branch Kosovo;
I.C. New Kosovo;
I.C. Safety;
I.C. Sigal-Grawe Group Austria;
I.C. Sigma.

\section{Legislation and Licensing Conditions in Kosovo}

The economy of our country, since the last war was destroyed completely, so after the war everything started from scratch. Development of a functional economy has been the duty and obligation of national and international institutions. In the context of the creation of such economic development, priority is given to the creation of the Banking and Payments Authority of Kosovo (BPK) later transformed into the Central Banking Authority of Kosovo (CBAK) and in 2008 it was appointed as the Central Bank (CB).

Creation of such financial institutions or authorities precedes the creation of a legislation and of legal infrastructure, 
based on the laws of a modern Western European market economy, thus creating a healthy and stable financial environment in comparison with other countries in the region. This helps in creating appropriate conditions for foreign financial institutions to increase the interest in investing in Kosovo. The creation of these financial mechanisms irrespective of their stage of development, have enabled the creation of conditions for development of an economy within existing environmental circumstances and Kosovo.

According to Article 9.1. the regulation on the licensing of an Insurance Company, one "can not engage in the business as insurance company or insurance intermediary in Kosovo, if it is not licensed from Central Bank". (CBK, The regulation on the licensing of an Insurance Company, 2009).

\section{Structure and Organization in Insurance Companies}

Usually all Insurance Companies use similar organizational chart, that it is managed and directed from its central department and from the operating units that executes the orders received by the Director, and they are located in different locations. Vertical structural work continues through subsidiaries that are located in big cities, that are continued with offices and sales points of operators.

The overall presentation of the organizational structure of a company is as follows:

Sector - Separation of competences

Division for product / insurance cover

Markets division

Division in sales channels

Tasks that belong to the respective sectors are divided as follows:

1. Analysis of competition and the needs of clients

2. Product Definition

3. The launch of the product

4. Insurance Needs Analysis

5. Defining risks and fees

6. Signing of contracts

7. Denunciation

8. Verification of damage

9. Assessment of damage

10. Liquidatio

11. Payment.

12. The investments

a. Investment Planning

b. Investment Management

13. Technical Reserves

Additional tasks which take place in an insurance company are: product development, strategic planning, marketing, internal organization, management control, internal audit, real estate management, support functions productive process, all of which are dependent on direct use of Information Systems (IS) respectively Information Technology (IT).

\section{Organizing the Company - Processes and Organization of Distribution Channels}

In general, structure for the compensation of accidents (accidents department) has autonomous functions of the importance of management "moment of truth" with the client. One of the core values of service for improvement of liquidation is the adoption of new information technologies for managing of distributed processes in the field.

Usually insurance companies in the country have started selling insurance products, policies TPL and TPLPLUS . The Organizational structures of companies in our country are composed of central directorate, organizational units and subsidiaries that are usually distributed in different regions of Kosovo, points of sale and operators offices.

Organizational Chart of a typical Insurance Company in Kosovo is presented below: 


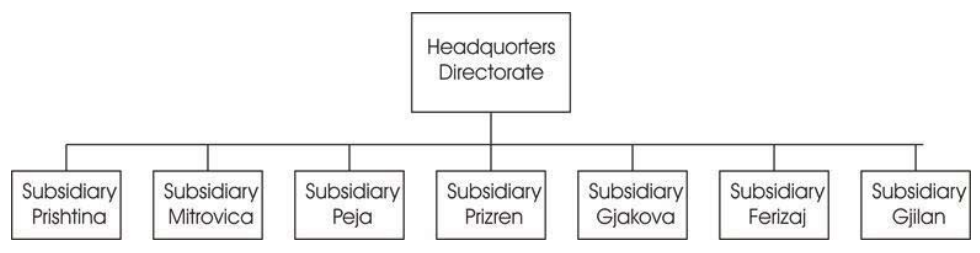

Figure 1: Diagram of the main lacotions of an insurance company in Kosovo

Source: Contribution from the authors

Improvement of the management of the customer report must always be in special focus.

Information System of the Insurance companies enables the specialization of products and the need to establish reliable reports that customer has brought in:

Presence of field operators

Preparation of highly specialized professional figures.

Faced with these needs, insurance companies have chosen the following solutions:

Management Agents of free structure (may be single or Plural-Mandatory), formed by an entrepreneur or more partners who promote sales of its products, commercial powers inside the territorial zone and the Guidelines arranged with insurance companies.

Intermediaries-consultants who are bridges between the insurance company, customer care, and Sector for Preparation of the contract. The consultant is insured and has no connection with the insurance company.

The Information System has to be developed in Insurance and credit institutions, with the possibilities which should:

See the possibility of lowering distribution costs

Create new market segments

Expand the potential market for investment reserves

Be financial promoters who are freelance professionals specializing on financial products.

Use forms of direct sales (telephone, Internet)

Use other distribution channels.

\section{Development of Information System, the Role and Importance of These Developments Inthe Advancements of Insurance Companies}

The information source is the key factor of development. The information presents constituent element of the right of freedom to use knowledge and therefore the company should provide an open system to such information.

Information system in insurance companies is among the most important ingredients for successful operation.

The insurance sector will usually be out of function, without the Information System based on information technology , since its operation is impossible without the use of various applications for: policyholders printing, reports, statistics, graphs, etc.

Information system is a system composed of people, data stored or activities that process the data and information, including manually processing or automatically. As the discipline of computer science, information systems research, does attempt to understand and justify the benefits of the affairs within the company and in particular in the insurance sector through information technology. Today, information technology and information itself have become one of the most important sources for the formation and executive leadership, along with people, money, materials and machinery.

Information system in the insurance sector can be defined as a set of interrelated components that collect, process, store and distribute information for decision making, coordination and control.

Information system in insurance companies helps leaders and operators in these companies to analyze problems and create new offerings on the market. The main role of the information system is that all operators, of all levels provides to the customers the right information at the right time, through which they can make decisions. 


\section{Hardware Equipment in a Sample Insurance Company in Kosovo}

In typical Insurance companies of Kosovo, the equipment of Information System is designed based on the needs of the Insurance Company with its branches in Kosovo. The Server is always installed at the Office of the director or manager of MIS department.

Based on our research, equipment with hardware devices, except in the main Server Center of the department of MIS, are usually comprised of several PC computers: with P4 processor with the frequency from 2.4Ghz to $3.5 \mathrm{GHz} / \mathrm{HDD}$ 40Gb to 500GB/RAM 4GB to 8GB / Monitor 15" to 19". Each computer has access to the Server and to a laser printer or plain Network Laser Printer. These devices allows users to access the Internet by VPN, with the exception of a few principal users who have also another second technical possibility to use the network from the different source. Access to the computers, Internet or VPN is arranged with the levels of authorization that are depended by the hierarchical employee position in the Organizational Chart of Insurance Company.

Equipment like Servers are positioned in different locations of the MIS department of the Insurance Company, and their maintenance is responsibility of the management of the company's information system.

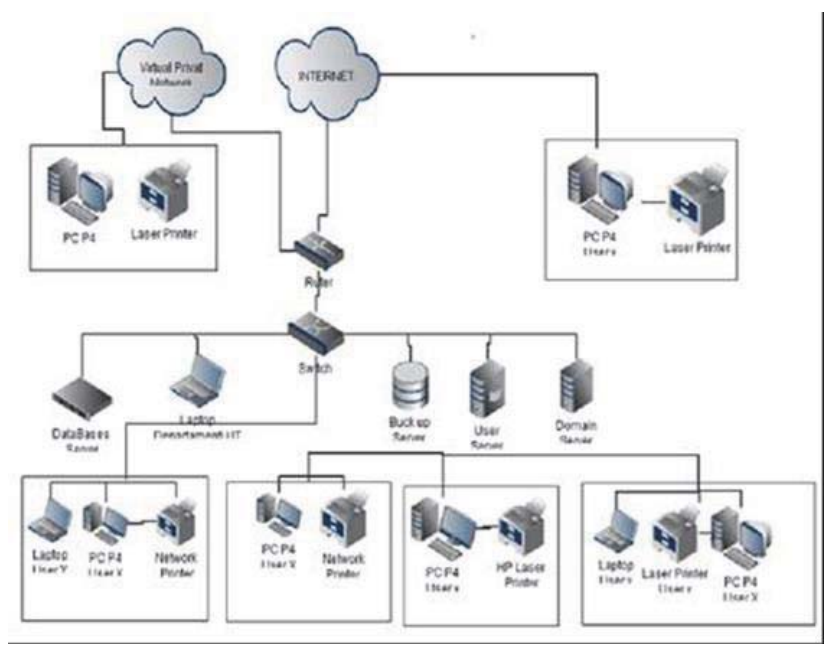

Figure 2: Tipical Network organization of Insurance Company in Kosovo

Source: Contribution from the authors based on situation in several IC-s

In most of insurance companies we noticed similar server specifications with: DELL/HP Xeon Quadro Core CPU 8GB to $16 \mathrm{~GB} ; 3$ to $4 \mathrm{GHz} / \mathrm{RAM}$ DDR2 8GB to $16 \mathrm{~GB} / \mathrm{HDD} 2 \times 500 \mathrm{~GB}$ to $2 \times 1 \mathrm{~TB}$ Lan. The operating router is standard 48-inch IPKO and Switches are CISCO Technology.

Besides these mentioned hardware facilities, insurance companies has some specific equipment and different Digital Camera and Copy equipment. These devices are needed to create the digital records for the needs of Insurance Company.

\section{Software of Information Systems in the Insurance Companies}

From the results of research of the paper, the authors have concluded that: Insurance companies in Kosovo in general use the Windows operating system, the software package Microsoft Office. In several cases for the administration of the server databases the Insurance Companies use OS Linux.

One of the most important applications that are in use in the IS of Insurance Companies is the application Software with the name IRIS, which is composed by the separate software components as follows:

口 "IPIS GIRO module" is the component that is relied on databases for the insurance category called "TPL" and "TPLplus" with the regulation how to print out "TPL" and "TPLplus";

口 $\quad$ "IAUA module" is the component for the administration with data and records management, that operators are 
generating,

- "IAS module" is the component of the Software, that is designed for cancelling of the generated documents and for the creation of temporary policies,

$\square \quad$ "IRRT module" is the component that is designed to create statics of the documents for damages, which is a very useful well made solution to calculate simultaneously the insurance risk,

$\square \quad$ "ICS module" is serving to record and to retain indication of damage with the possibility to create different kinds of reports for stocks, damage payments etc.

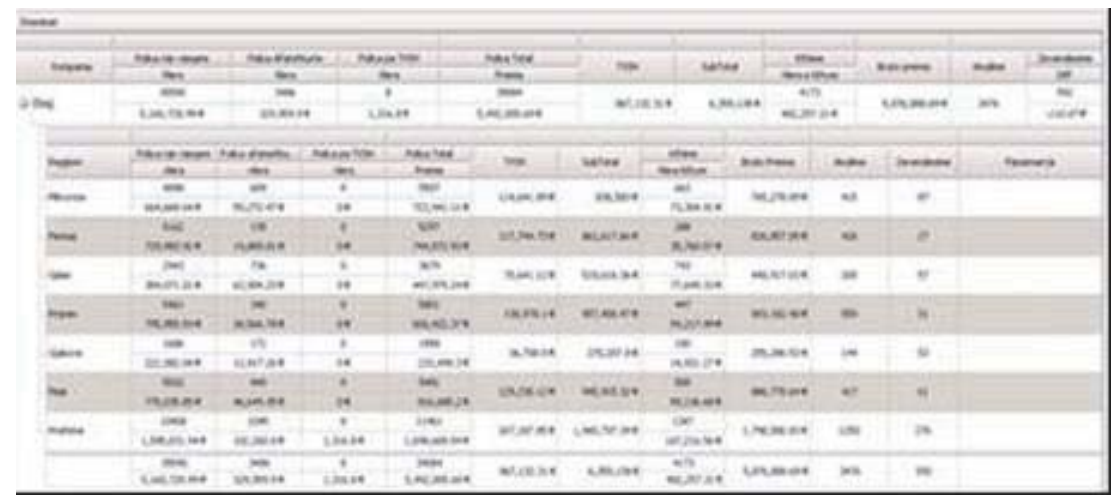

Figure 3: Form of "IRRT" module that presents certain period of realization by the number and value of TPL policy.

Source: Contribution from the authors

"Module IRRT" is used mainly by the officers of Insurance companies, that deal with the analysis of results of the operators for a certain periods of time. This module also enables the possibility to browse the detailed and summary reports of damage from the policy and from the operators. One of the specific values in the statistics is the ratio for calculating insurance risk underwriting for TPL holder simpler technologies that are shown in the form below:

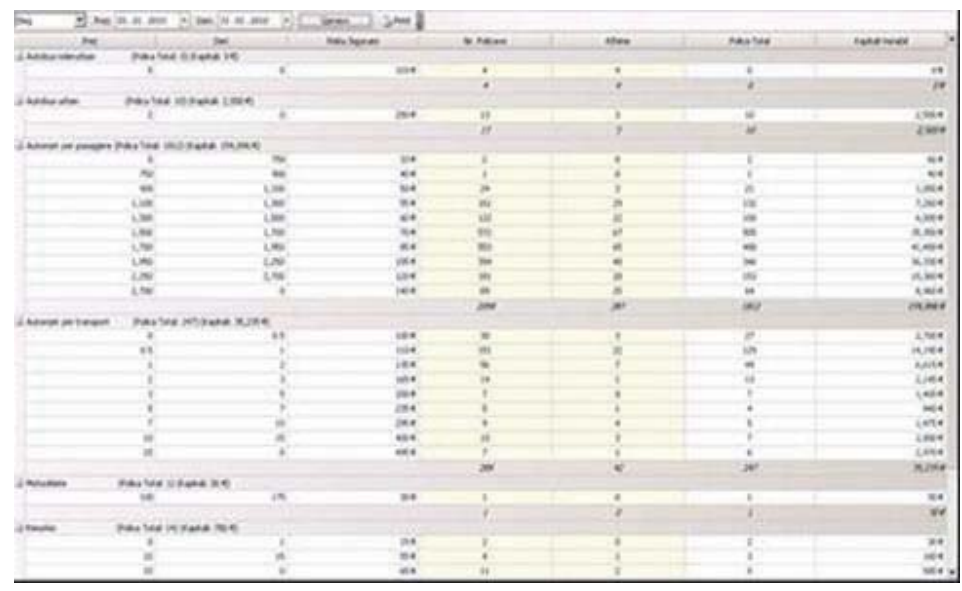

Figure 4: Form of "IRRT" module

Source: Contribution from the authors

The creation of TPL policy and TPLplus, is made by operators in offices that are located in various locations throughout the territory of Kosovo. Module "IPIS" as a basic module is designed for the policy databases of customers and vehicles and enables filling on it. 


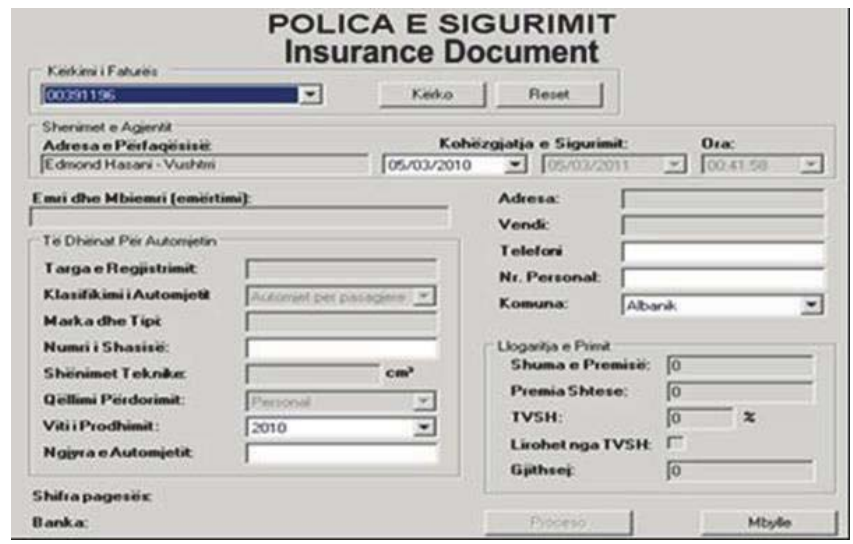

Figure 5: Form of IPIS GIRO for creation of Insurance Document for a certain period of time Source: Contribution from the authors

\section{The Review of Policies for Operatorscreated for a Certain Period}

The form with the structure of data in the table of TPL and TPLPLUS insurance database, is as follows:

Table: The form with the structure of data in the table of TPL and TPLPLUS insurance database

\begin{tabular}{|c|c|c|c|c|c|c|c|c|c|c|c|}
\hline meige & monons & tostre & unstumes & mese & canse & $\min$ & wat & $\tan$ & moner & $\operatorname{sen} 0$ & manes \\
\hline 20sxos, & Laseroes & 12062000 & ags neav & mogene & w ww masew suats & 10900 & is & 120,5 & 12012000 & $\operatorname{man}$ & nimoven \\
\hline 20013: & awprase & $12007 / 2000$ & vanorisy & mesp & whusvopaw inot & 20000 & 19 & $24: 50$ & achrason & ates & atopas \\
\hline souts & Wenrases & $2607 / 2006$ & show esumanr tans. & aschess & wowerksistsens & 50000 & $g$ & $n \times \infty$ & 260012500 & $\operatorname{san}$ & svereses \\
\hline 200an & wow:sot & 4002006 & Autos wates & Alaches & maspousens & $13 \infty$ & 10 & $n n$ & waseroon & $m$ & arevoces \\
\hline $20 x a n$ & LAsourases & $1100 / 2000$ & 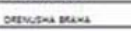 & mesas & Woolvaturouss & 3000 & 13 & 010 & Wa/2004 & aมs & $m$ \\
\hline 20eans & axow 200 a & 260t:2000 & 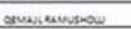 & escegat & wrw matountosus & $\cos \infty$ & is & 2200 & wowasoen & เак & nimin \\
\hline mansese & awsersos & woe:200 & Mvau geatuve & Aneras, & wWw mmusw vesans & 19000 & is & 2490 & swousocet & an: & mons \\
\hline mones: & Qwow/2004 & aron:oces & motreste & sorasn & W cusmas:move & weos & 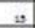 & 20900 & seco:/2006 & $\sin$ & nare \\
\hline mass, & cescosea & $\$ 00 / 2000$ & stareon & & WNAT2acTs:Ma:aen & $\sin \infty$ & 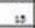 & 20190 & 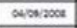 & $a$ & $\operatorname{sen}$ \\
\hline 2006es & Q60:200s & otowrsest & maver & measos & whovevososvam & 20000 & 19 & 2490 & 6606:2000 & am & moge \\
\hline $\operatorname{mos}$ & 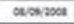 & 00062000 & nueugn & sursonu & Wuscemrovem: & 40400 & 19 & $2 a: 12$ & cescas:00e & $m$ & $\tan$ \\
\hline
\end{tabular}

Source: Contribution from the authors

Applications for TPL, TPL Plus policies and for the evidence of damage are usually computer programs that are created by the external contractor. These applications are installed on shared servers of all insurance companies that are registered in the Central Bank of Kosovo. Access to these programs is through the VPN network which is implemented and maintained by external contractors. These applications function in networks at any point with the dedicated VPN, installed specially only for insurance companies. Quality, safety of data and of applications into the net level are high.

Companies are also functional in other applications that are pertaining to the insurance field:

Integral based Application for calculating of the premium data transmission, different reporting to CBK needs and tax administration.

Application for Accounting and Finance

Personal Accident Insurance Application

Application for Casco insurance of vehicles

Application for travel health insurance

Insurance Application for tenders and contracts

Application for insurance of property

Application for life insurance.

Other security applications that are developed in MS Access database, these applications can work as special 
applications on a computer and applications for many users. An application apparance of Casco insurance of vehicles is shown below.

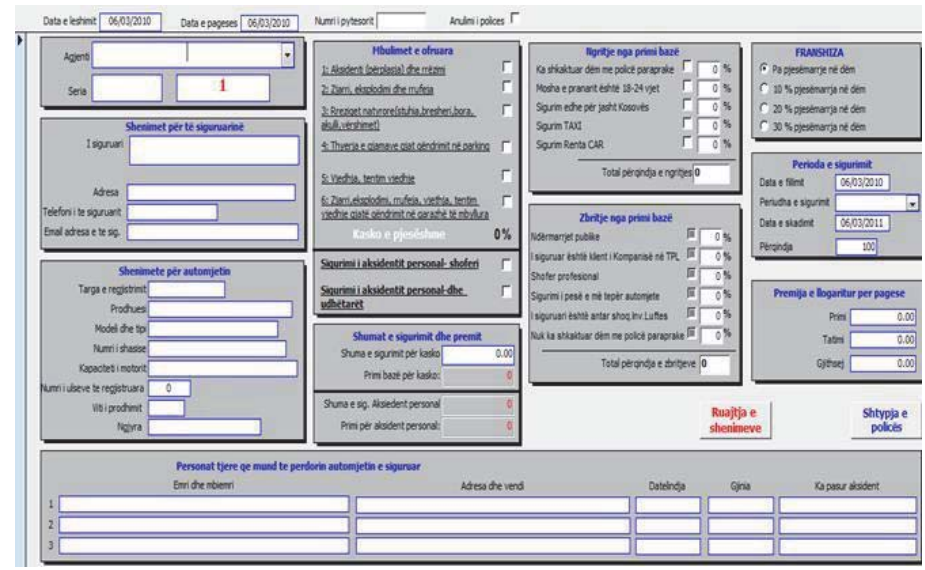

Figure 6: An application apparance of Casco insurance of vehicles Source: Contribution from the authors

This application enables interactive work for the premium calculation by modifying the input parameters.

All other applications for insurance are built in order to provide an easy taskto use and enables interactive calculation value for the insurance premium.

\section{The Main Form for the Provision of People Who have had Accident}

One of the most important application of Information System in Insurance Companies is an integral basis for calculating of all different types of insurance. Some reports that are generated in table form by time periods will be presented below:

\begin{tabular}{|c|c|c|c|c|c|c|c|c|c|c|c|c|}
\hline \multicolumn{13}{|c|}{ Total of premiums based on type of Insurance $\quad 09 / 2014$} \\
\hline Produkti & then & Promp & नVभH & बratsi & pirpol & Weas & 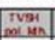 & Gowim & 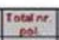 & rost & $\begin{array}{l}\text { Toon } \\
\text { tVMr }\end{array}$ & TOFAL \\
\hline $01.2 \pi$ & 212 & गw1ब & प्रत्रा4 & WLISA & II & 70009 & 12242 & $19 x$ & 2004 & $20 \times 50$ & $2268 x$ & 70xs: \\
\hline $09.2 \pi \cdot \pi \cdot 03$ & 23 & क्र 620 & एक्ष & 110ut & 2 & 204 & है। & सर्य & $2 \pi$ & 2005 & 1320 & 10ख्या4 \\
\hline 77-kake & 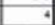 & 1700 & अa: & 200013 & 8 & col & oco & क्व & & मानल & 3016 & 200011 \\
\hline 10.5Lendes = Vdhrim & $\log 0$ & $24 \times 124$ & 1क्या & 2mest & 8 & nes & कास्स & कास्न & Wक्ष & 2500/ & ग0ल & $23 \% \approx 2$ \\
\hline 19 - Bid Bond & 30 & $\operatorname{sen} x$ & $5 x$ & खथक्ण & 3 & 340 & 104 & बa & गी & I.50 & s.s. & सबान्य \\
\hline Grasd Total & 3,951 & monsen & क्या & an, & of & 7936 & $1200 \mathrm{se}$ & 92065 & 3,24 & 2003nez? & sinese & estist \\
\hline
\end{tabular}

Figure 7: Generated Report of the premises and the number of insurance policies by type for a given month. Source: Contribution from the authors

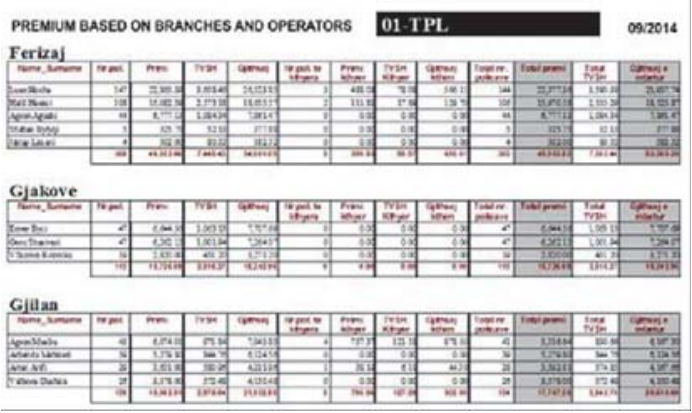

Figure 8: Generated form from IS with the Report of the premium and the number of policyholders by affiliates, operators and providing for a given month.

Source: Contribution from the authors 
A very important report that is used for determining the solvency of an insurance company is also carrying calculationof the premium.

\begin{tabular}{|c|c|c|c|c|c|c|}
\hline \multicolumn{4}{|c|}{ Transferred Premium } & \multicolumn{3}{|c|}{$01 / 01 / 2015-31 / 03 / 2015$} \\
\hline \multicolumn{4}{|c|}{ 01-TPL } & \multirow[b]{2}{*}{ Dermia } & \multirow[b]{2}{*}{ pnm_t } & \multirow[b]{2}{*}{ crim ba } \\
\hline & deta_tia & cata mos & arpost & & & \\
\hline & लकखलm & करण:50 & $\frac{3}{3}$ & $\begin{array}{ll}70,41 \\
10041\end{array}$ & 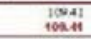 & 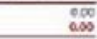 \\
\hline sum & $\cos 30$ & $\theta 00 \times 00$ & $\frac{1}{22}$ & Wass & 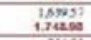 & 2000 \\
\hline \multirow{2}{*}{ som } & $\omega \infty \times \times=$ & $\alpha \infty \times 20$ & $\frac{44}{x}$ & 2,8459 & 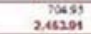 & $\begin{array}{ll}600 \\
0 \infty 00\end{array}$ \\
\hline & 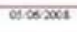 & ल) & in & 50100 & 20756 & 600 \\
\hline \multirow{2}{*}{ sum } & $0000 \times 5 \times 1$ & $\infty 00 \times 50$ & $\frac{19}{19}$ & $\frac{2.3401}{1.099}$ & $\frac{208019}{2.0059}$ & $\frac{.000}{.00}$ \\
\hline & & 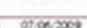 & 62 & $275 x$ & $2+150$ & 200 \\
\hline \multirow{2}{*}{ sum } & 67000000 & $0+00.000$ & 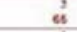 & 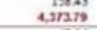 & . & 600 \\
\hline & 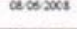 & 000000 & $\alpha^{2}$ & 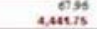 & asis & $\begin{array}{l}6 \infty \\
0 \infty \infty\end{array}$ \\
\hline & sorant & 000000 & $\stackrel{y}{*}$ & 14211 & 1.4213 & $\because \infty$ \\
\hline & $1000 \times 001$ & $1000 \times 00$ & 18 & 197535 & 2.1759 & .000 \\
\hline \multirow{2}{*}{ sum } & 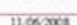 & & $\operatorname{tos}$ & Doesst & resset & 200 \\
\hline & 1062000 & 1002000 & aiz & 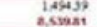 & 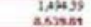 & $=000$ \\
\hline
\end{tabular}

Figure 9: Generated form from IS with the Report of the transfered premium for a given Period Source: Contribution from the authors

This generated report from the Information System is detailed and reflects the number of policies created for each day,enabling the calculation of the premium, the premium earned and unearned premium from the point of a certain period, giving total general parameters listed at the end of each day.

\section{Important Details from the Software of Information Systems in the Insurance Companies}

\subsection{Customer data information}

Information System and technology should be safe and have the storage capacity of the large number of operations for clients, their addresses, phone numbers, email addresses and other relevant details. For the purpose of operators insurance companies keep records about their customers details.

\subsection{Data on insurance policies}

Information System and technology becomes day by day more complex, for all those companies that issue insurance policy through various lines of insurance. Details from any officers, ranging from life insurance, house, car, business products, need to be handled carefully and also placed in the client record.

\subsection{Claims Management}

Investigation, payment and recording of data is fundamental for financial stability of insurance companies. Information System and technology plays a crucial role, in allowing the operators to record details of the damage and to share information with the police, with other operators, with causers of the damage or with beneficiary.

\subsection{Beneficiaries}

Life insurance companies are obligated to use database technology for the benefits of the registered property policies. Besides the personal details of individuals in the insurance policy, they also provide the beneficiaries' names, addresses, telephone numbers and of the information that belongs to them in case of death. These details are of particular importance.

\subsection{Transparancy on Information and online presence of Insurance Companies in Kosovo}

Perhaps the most essential areas which require an efficient information technology are the customer's payment details. Besides other operations, the Information system has to generate billing, as a business opportunity to stay in the market. Cash Flow is of vital importance for the company, in its daily activities and if there is a lack of technical assistance and 
information processing systems, the company will be put at risk in its financial stability.

Great revolutionary changes in technology have revolutionized the entire Sector of insurance. The insurance industry is an industry with a lot of things, data, and thus, it is necessary that this information be used for trend analysis and personalization. With increasing competition among providers, this service has become a key service. Moreover, customers are becoming more demanding and interested in the technology by which insurers operate.

Information Technology gave great inputs to the insurance companies and through its efficiency can reach tasks better for policyholders. Developing technology also helps in another direction, it enables management to review performance and take corrective action when necessary.

In Kosovo this technology is not yet optimized and following the development of information technology in EU countries would be appropriate to change gradually as a first challenge.Today we have the revolutionary changes in communication with policyholders, and various steps have been takenin the developed countries. Inter-Voice Response System is introduced in such a way that policyholders can find different types of information such as the stateof the policy, the position of the premium, the loan amount, benefits, bonus collection. This ensures that premium payment or generated reports on the condition of the reinstatement, credit or delivery fees at any branch which is in the land of his nearest residence.

E-mail links are created in every office, of every department at all regional offices and headquarters. Various websites are created with the purpose of connecting to the Internet and through which the company provides information about the organization, product or service. Such web-sites are well established in Kosovo today, and we have counted several of them, such as: www.dardania.com, www.kosovaere.com, www.illyriainsurance.com, www.sigma-ks.net, www.ks-siguria.com, www.elsig.com etc, www.sigal-ks.net etc.

\section{Conclusion}

This research paper would raise technical, professional and commercial issues that reflect with the reality of modern insurance agencies and Information Technology. The insurance itself contains problems of different nature, which have to be overtaken and at the same time find the solutions that meet with the customers' needs.

The paper, provides ideas and new techniques of development of the insurance industry in Kosovo. During elaboration of its practical facts, the application of information technology in insurance companies in Kosovo was taken into consideration, and the same have been simplified as far as it was possible.

The history and development of insurance companies and their role toward economic development is also presented in the paper in a comprehensive way, in relation to reducing of the level of unemployment as well as providing of more qualitative services for customers of these companies. In particular, paper presents the importance of information technology in business and to what extension it has facilitated the work performance and the experience, how has technology replaced the man in performing of activities which have been difficult to accomplish.

Nowadays the Information Technology is presented as an indispensable need in every sphere of life and as such it is also applicable with the insurance industry.

The existence of insurance companies in Kosovo and worldwide, cannot be imagined without information technology and its application. In recent years the Information Technology is applied in all spheres of Insurance business.

\section{References}

Bakraçi, Xhevad, Risk Management and Insurance, Pristina, 2004

Beqiri Edmond, Interneti - komunikimet kompjuterike, IOM; International Organization for Migration; Dukagjini; UP 2002

Beqiri Edmond, Bazat e informatikës, University of Prishtina; Universiteti i Prishtinës; UP 2006

Beqiri, Edmond, Management Information Systems, European Vision University, 2008

Beqiri Edmond, Ekonomia digjitale dhe biznesi elektronik, KED, Pejë, 2012

Dickson M, "Introduction to insurance", Cambridge, 1984

Haag, Cummings \& McCubbrey, Management Information system for the Information Age, 2005

James A. Sen. Information Technology in Insurance Companies, Pearson Prentice Hall, 2004

Morton, Keller, The life insurance enterprise, Cambridge 1963

Practical Research made in person at the insurance companies operating in Kosovo.

Stephen D.Tamsey, Business Information Technology and Society, Routledge, 2003

White, W.R. The coming transformation of Business, London, 2004

CBK, The regulation on the licensing of an Insurance Company, 2009 